\title{
Evaluation of Early Warning Indicators (EWI) of HIV Drug Resistance According to the World Health Organization (WHO) in Some Treatment Centers in Kinshasa
}

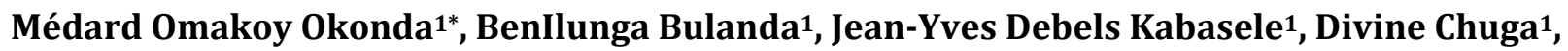 \\ Berry Ikolango Bonganya ${ }^{1}$, Erick Ntambwe Kamangu1,2* \\ ${ }^{1}$ Research Group “Focus HIV/AIDS”, Kinshasa, Democratic Republic of Congo (DRC) \\ ${ }^{2}$ Molecular Biochemistry Service, Department of Basic Sciences, Faculty of Medicine, University of Kinshasa (UNIKIN), Kinshasa, \\ Democratic Republic of Congo (DRC) \\ Email: *medardokonda@gmail.com, *erick.kamangu@unikin.ac.cd
}

How to cite this paper: Okonda, M.O., Bulanda, B., Kabasele, J.-Y.D., Chuga, D., Bonganya, B.I. and Kamangu, E.N. (2019) Evaluation of Early Warning Indicators (EWI) of HIV Drug Resistance According to the World Health Organization (WHO) in Some Treatment Centers in Kinshasa. Open Access Library Journal, 6: e5500. https://doi.org/10.4236/oalib.1105500

Received: May 24, 2019

Accepted: July 26, 2019

Published: July 29, 2019

Copyright $\odot 2019$ by author(s) and Open Access Library Inc.

This work is licensed under the Creative Commons Attribution International License (CC BY 4.0).

http://creativecommons.org/licenses/by/4.0/

\begin{abstract}
Background: The Early Warning Indicators (EWI) of Human Immunodeficiency Virus (HIV) Drug Resistance measure factors found at the site level and known to be associated with the proper functioning of the program and the prevention of the emergence of R-ARV. The fact strengthening certain aspects of implementation of the program at the sites can help minimize the occurring of HIV Drug Resistance that can be prevented to improve the long-term effectiveness and sustainability of the treatment. Objective: The objective of this study was to assess the quality of the prevention of resistance of HIV Drug compared to EWI set by the World Health Organization (WHO) in the different Ambulatory Treatment Centers (ACT) in the city of Kinshasa. Methods: The present work was a retrospective survey conducted in 2015 in 7 ACTs in the 4 districts of Kinshasa in order to evaluate the EWI. Results: Seven (7) ATCs and 157 patient records were selected based on different inclusion criteria. The maintenance of first-line Antiretroviral Treatment (ART) at 12 months and the consistent delivery of ARVs were the two EWI that were respected, evaluation at $100 \%$, for 6 ACTs. Conclusion: The caregivers and HIV-infected patients should be trained on the EWI and their monitoring to prevent the occurrence of treatment failures and that of HIV drug resistance in Kinshasa.
\end{abstract}

\section{Subject Areas}

HIV, Public Health 
Keywords

Early Warning Indicators, HIV Drug Resistance, WHO, Kinshasa

\section{Background}

The emergence of some degree of Human Immunodeficiency Virus (HIV) Resistance to Antiretroviral Drugs (HIVDR) is unavoidable in populations receiving Antiretroviral Treatment (ART), even if the regimens provided are appropriate and patients are supported to better observe their treatment [1]. This is because mistakes often occur during the replication of HIV, the high rates of mutation that selects pressure on ARVs give rise to new viral recombination, and the fact that the treatment must be provided for a lifetime [1].

Surveys conducted by the World Health Organization (WHO) in 12 Low or Middle Income Countries (LMIC) show that many health facilities currently lose contact to up to $38 \%$ of the patients on ART in their cohort [2]. This loss of contact represents a serious threat to the control of ARV resistance because most of these patients interrupt or completely stop their treatment. This means that they expose themselves to becoming sick but also to increasing the risk of developing HIVDR and transmitting the virus resistant to other people [3].

According to the Global WHO report in 2010 on monitoring of Patient Living with HIV (PLHIV), the use of ART in LMIC had led the development of resistance to some forms of treatment but not in the same proportions as when the first ART was highly marketed in the 1990s [2] [3]. In 2016, more than 8 million people were now on ARVs in LMIC while they were only 4000 in 2003 [2]. In 2010, the proportion of ARV-resistant cases among people starting ART in the reporting LMICs was 6.8\% [2]. Over a comparable period, after the introduction of ARVs in high-income countries (HIC), slightly higher HIVDR rates of $8 \%$ to $14 \%$ depending on the region were observed [2]. In its report, WHO recommends that any center providing ARTs uses a set of "Early Warning Indicators" (EWI) to identify and treat factors that could lead to drug resistance. These EWIs include: 1) the practice of prescribing ART, 2) patients lost of sight during the first 12 months of $A R T, 3)$ patients on an appropriate first-line regimen for 12 months, 4) receiving $A R V$ s on time, 5) respect of $A R T$ appointments, 6) constancy of $A R V$ delivery, 7) observation of ART by patients, and 8) suppression of Viral Load (VL) 12 months after initiating ART. In Kinshasa, the HIVDR rate among patients initiating ART was around 8\% in 2014 [3] [4]. Thus the objective of this study was to evaluate the quality of the prevention of the occurrence of treatment failures and the HIVDR compared to EWI according to WHO some Ambulatory Treatment Centers (ATCs) of Kinshasa.

\section{Methods}

\subsection{Frame}

This study was a retrospective survey that was conducted in 7 Ambulatory 
Treatment Centers (ATCs) in 4 different districts of Kinshasa, in the Democratic Republic of Congo (DRC), by consulting patient records initiating ART in period from January 2014 to June 2015. The ATCs were selected randomly in respect of 2 ATCs per district of Kinshasa.

\subsection{Centers and Patient Records}

All ATCs located in one of the 4 different districts of Kinshasa were included in the survey. They should be recognized as ATCs for more than 2 years, with records of ARV patients initiated in the center with an electronic database. Records containing all relevant information for EWI, having a starting date of ART, having an initial or second-line ART regimen known (for those on ART for at least one year), and files of patients aged over 18 years were selected for this work. The following parameters were used to evaluate the EWI: the patient's information, type of HIV, co-infection associated with HIV, date of initiation of ART, initial ART regimen, date of last referral appointment, date of last ARV withdrawal, baseline regimen (if different), dates of all ARV withdrawals for the first 12 months, date of consultation appointments completed after initiation of ART, percentage of tablets taken, date of Viral Load (VL) evaluation, VL result.

After the determination and confirmation of the quality and completeness required for EWI surveillance, only 157 patient files meeting the inclusion criteria were selected for the follow-up of different EWI according to the recommendations of the national program [5] [6].

\subsection{Ethical Clearance}

Each center involved in the work had given its consent for the collection and publication of data. The study had also received consent and clearance from the Institutional Review Board.

\section{Results}

Seven centers and 157 patient files initiating ART were selected based on inclusion criteria for the surveillance of $8 \mathrm{EWI}$. For all 7 centers, $\mathrm{EWI}_{3}$ and $\mathrm{EWI}_{6}$ were well followed by 6 ACTs, followed by $\mathrm{EWI}_{2}$ followed at $42 \%$, then $\mathrm{EWI}_{1}$ followed at $14 \%$, no center reached the targets for $\mathrm{EWI}_{4}$ and $\mathrm{EWI}_{5}, \mathrm{EWI}_{7}$ and $\mathrm{EWI}_{8}$ have not been evaluated as they are not routinely applied in the ACTs in Kinshasa. The above data are detailed in the following tables. Table 1 presents the relationship among the objectives set for evaluation and the results obtained in each center. While Table 2 presents the level of achievement of the different EWI by the centers.

\section{Discussion}

The objective of this study was to evaluate the quality of the prevention of the occurrence of treatment failures and the HIV Drug Resistance (HIVDR) compared to Early Warning Indicators (EWI) according to the World Health 
Table 1. Results in relation to the objectives set and results obtained for all ATCs.

\begin{tabular}{|c|c|c|}
\hline indicators & $\begin{array}{l}\text { Objective to reach } \\
\text { for each EWI }\end{array}$ & $\begin{array}{l}\text { Number of ATCs meeting the target } \\
\text { (\% of ACTs with the target set) } \\
\text { N = 7 ATCs }\end{array}$ \\
\hline $\mathrm{EWI}_{1}$ : Practice of prescribing ART & $100 \%$ & $1 / 7(14 \%)$ \\
\hline $\mathrm{EWI}_{2}$ : Patients lost of sight during the first 12 months of ART. & $\leq 20 \%$. & $3 / 7(42 \%)$ \\
\hline $\mathrm{EWI}_{3}$ : Patients on an appropriate first-line regimen for 12 months. & $\geq 70 \%$ & $6 / 7(85.7 \%)$ \\
\hline $\mathrm{EWI}_{4}$ : Receiving ARVs on time. & $\geq 90 \%$ & $0 / 7(0 \%)$ \\
\hline EWI $I_{5}$ Respect of ART appointments. & $>80 \%$. & $0 / 7(0 \%)$ \\
\hline $\begin{array}{l}\text { EWI }_{6} \text { : Constancy of ARV delivery. Number of months } \\
\text { without any rupture of stock in } 1 \text { year }\end{array}$ & $100 \%$ & $6 / 7(85.7 \%)$ \\
\hline $\mathrm{EWI}_{7}$ : Observation of ART by patients. & $\geq 90 \%$. & $0 / 7(0 \%)$ \\
\hline EWI & $\geq 70 \%$. & $0 / 7(0 \%)$ \\
\hline
\end{tabular}

Based on the different objectives set for each EWI, this table shows that for all the ATCs selected in our study, only 2 EWIs (3 and 6) were achieved at 100\% completion.

Table 2. Overall results of different EWI on each ATC.

\begin{tabular}{|c|c|c|c|c|c|c|c|c|}
\hline ATC & $\begin{array}{c}\mathrm{EWI}_{1} \text { : } \\
\text { Practice of } \\
\text { prescribing } \\
\text { ART. } \\
\text { Objective: } \\
100 \%\end{array}$ & $\begin{array}{c}\text { EWI }_{2} \text { : } \\
\text { Patients lost } \\
\text { of sight during } \\
\text { the first } 12 \\
\text { months of ART. } \\
\text { Objective: } \\
\leq \mathbf{2 0} \%\end{array}$ & $\begin{array}{c}\mathrm{EWI}_{3} \text { : } \\
\text { Patients on } \\
\text { an appropriate } \\
\text { first-line } \\
\text { regimen for } \\
12 \text { months. } \\
\text { Objective: } \\
\geq 70 \%\end{array}$ & $\begin{array}{c}\text { EWI } \\
\text { Receiving } \\
\text { ARVs on time. } \\
\text { Objective: } \\
\geq 90 \%\end{array}$ & $\begin{array}{c}\text { EWI }_{5} \text { : } \\
\text { Respect } \\
\text { of ART } \\
\text { appointments. } \\
\text { Objective: } \\
>\mathbf{8 0} \%\end{array}$ & $\begin{array}{c}\text { EWI }_{6} \text { : } \\
\text { Constancy of } \\
\text { ARV delivery. } \\
\text { Number of } \\
\text { months without } \\
\text { any rupture of } \\
\text { stock in } 1 \text { year } \\
\text { Objective: } 100 \%\end{array}$ & $\begin{array}{c}\text { EWI }_{7} \text { : } \\
\text { Observation } \\
\text { of ART by } \\
\text { patients. } \\
\text { Objective: } \\
\geq 90 \%\end{array}$ & $\begin{array}{c}\text { EWI }_{8} \text { : } \\
\text { Suppression of } \\
\text { Viral Load (VL) } \\
12 \text { months after } \\
\text { initiating ART. } \\
\text { Objective: } \geq 70 \%\end{array}$ \\
\hline 1 & $6 / 12(50 \%)$ & $4 / 12(33 \%)$ & $12 / 12(100 \%)$ & $9 / 12(75 \%)$ & $5 / 12(41 \%)$ & $12 / 12(100 \%)$ & $0 / 12(0 \%)$ & $0 / 12(0 \%)$ \\
\hline 2 & $7 / 11(63 \%)$ & $2 / 11(18 \%)$ & 9/11 (81\%) & $3 / 11(27 \%)$ & $2 / 11(18 \%)$ & $12 / 12(100 \%)$ & $0 / 11(0 \%)$ & $0 / 11(0 \%)$ \\
\hline 3 & $11 / 30(36 \%)$ & $7 / 30(23 \%)$ & $30 / 30(100 \%)$ & $16 / 30(53 \%)$ & $8 / 30(26 \%)$ & $12 / 12(100 \%)$ & $0 / 30(0 \%)$ & $0 / 30(0 \%)$ \\
\hline 4 & $19 / 26(73 \%)$ & $5 / 26(19 \%)$ & $26 / 26(100 \%)$ & $17 / 26(65 \%)$ & $15 / 26(57 \%)$ & $12 / 12(100 \%)$ & $0 / 26(0 \%)$ & $0 / 26(0 \%)$ \\
\hline 5 & $19 / 33(57 \%)$ & $3 / 33(9 \%)$ & $31 / 33(93 \%)$ & $15 / 33(45 \%)$ & $14 / 33(42 \%)$ & $12 / 12(100 \%)$ & $0 / 33(0 \%)$ & $0 / 33(0 \%)$ \\
\hline 6 & $45 / 45(100 \%)$ & $9 / 45(20 \%)$ & $45 / 45(100 \%)$ & $27 / 45(57 \%)$ & $10 / 45(22 \%)$ & $12 / 12(100 \%)$ & $0 / 45(0 \%)$ & $0 / 45(0 \%)$ \\
\hline 7 & - & - & - & - & - & - & - & - \\
\hline
\end{tabular}

The data on ATC number 7 are not included in this table because no file of that ATC did fulfill the inclusion criteria for the evaluation of EWI.

Organization (WHO) some Ambulatory Treatment Centers (ATCs) of Kinshasa.

$\mathrm{EWI}_{1}$, on ARV prescription practice, has the purpose of calculating the percentage of patients initiating appropriated first-line ART in selected ATC, where the ART was originally prescribed in pharmacy. $\mathrm{EWI}_{1}$ was respected at $14 \%$ on all ATCs while the targeted objective is at $100 \%$. The prescribed ART in different ATCs in Kinshasa did not comply with the national guideline; most centers prescribe what they have in hand. This was previously evaluated by Botomwito who presented the same discrepancy [7]. This non-compliance was also found in Cameroon in a study which evaluated the EWI [8]. This is due to the fact that HIV care providers and prescribers of ARVs do not strictly follow the WHO's 
recommendations on treatment, the large number of ARV circulating in LMIC without regulation, and the poor understanding and knowledge of this EWI and its surveillance [7] [8]. This EWI is not met in the evaluated ATCs.

$\mathrm{EWI}_{2}$, on patients lost in the follow-up cohort during the first 12 months of ART, was evaluated to determine the percentage of patients initiating ART in specific centers and who were lost of sight of in the 12 months following the start of the treatment. This EWI was respected at $58 \%$ of all ATCs thus giving a rate of $42 \%$ of patients lost sight in the first year while the targeted objective is less than $20 \%$ of patients lost of sight. This high rate of patients lost of sight had also been presented in previous studies in Kinshasa [9] [10]. This high rate of patients lost of sight was most likely due to the fact that most patients are not well aware of the fact that ART is a treatment for life once it is started; regardless of the improvement in the state of health. This EWI is not met in the evaluated ATCs.

$\mathrm{EWI}_{3}$, on appropriate first-line ART during the first 12 months, has the purpose of determining the percentage of patients initiating appropriate first-line ART according to national guideline in different ATCs. This EWI was respected at $85.7 \%$ of all centers while the objective set is over $70 \%$. This EWI was respected by the centers even thought they did not apply to that. This EWI is met in the evaluated ATCs and can be improved to assure better care of patients.

$\mathrm{EWI}_{4}$, on receiving ARV on time, has the purpose to evaluate the distribution and the time interval for patient's reception of drugs by evaluating the percentage of patients initiating ART who withdrew their prescribed drugs on a timely basis within the first 12 months once initiating treatment. This EWI was not respected in any center selected for the survey for it was not followed by the patients or care-givers in the centers. Most patients and care-givers in LMIC do not grasp the importance of time frame in drug withdrawal as a factor of maintaining good quality of health. This had also been proven in a similar study in Cameroon [8]. This EWI is not met in the evaluated ATCs.

$\mathrm{EWI}_{5}$, on respect of consultation appointments for patients given by care-givers, has the purpose to determine the percentage of patients initiating ART who met all scheduled or expected consultation appointments in a timely manner for the first 12 months of ART once initiated. This EWI has not been respected in any ATCs by patients while the targeted objective set is over $80 \%$. Just like $\mathrm{EWI}_{4}$, this EWI is not properly understood by both parties, patients and care-givers. The appointments are usually scheduled by care-givers in accord with the patients [7]. However, the lack of respect of appointment should be notified as sanction for patients in order to strengthen this aspect. This lack of respect is due to the fact that patients are poorly informed about the importance in respecting the scheduled appointment for improving their follow-up. This EWI is not met in the evaluated ATCs.

$\mathrm{EWI}_{6}$, on the consistency of ARV delivery in the ATC expressed in number of months without any rupture of stock in the first year, aims to determine the number of months during which there was no stock outage while taking care of 
patients. This EWI was entirely respected for 6 ATCs (100\%) out of the 7 selected as the targeted objective set is at $100 \%$. For the year selected, 2014, there was no outage of drugs in the selected centers as they were all furnished by the national program and its different partners to assure constant deliver. This EWI was also respected in Cameroon [8]. This EWI is met in 6 out of 7 evaluated ATCs.

$\mathrm{EWI}_{7}$, on the observation of ART by patients included in the line of treatment by presenting the percentage of patient initiating treatment and respecting it, aims to evaluate the adherence of patients in the treatment by counting the number of tablets on the next appointment. This EWI was not evaluated in the selected ATCs while the targeted objective set is at $100 \%$. The count of tablets was not evaluated because this is not done nor recommended in the centers. It is very difficult in the centers to demonstrate or prove that all ARVs prescribed and provided to patients were counted tablet by tablet on delivery and tablets remaining at the next scheduled appointment. Therefore, This EWI is not met in the evaluated ATCs.

$\mathrm{EWI}_{8}$, on suppression of Viral Load (VL) 12 months after initiation of ART, aimsto determine the percentage of patients under ART followed in the ATC whose VL is less than $1000 \mathrm{RNA}$ copies/ml or undetectable 12 months after initiating ART. This EWI could not been evaluated since the VL is not yet a routine examination in different ATCs in Kinshasa because this test is not available routinely and of its high cost estimated by patients in relation to their socio-economic level. Thus, this EWI is not met in the evaluated ATCs.

The evaluation of the EWIs is still a burden for different ATCs in Kinshasa. Two out of eight EWI $\left(E W I_{3}\right.$ and $\left.E W I_{6}\right)$ were respected in the selected ATCs according to the recommendations.

\section{Conclusion}

In view of these results and based on the objectives, the prevention of HIV resistance based on EWI is a practice not yet well known and applied in ATCs in Kinshasa. Caregivers should be trained to monitor EWI, which will contribute to good care and effective prevention of the occurrence of treatment failure and that of HIV resistance in patients on Antiretroviral Treatment in Ambulatory Treatment Centers of Kinshasa.

\section{Authors' Contribution}

MOO, $\mathrm{BIB}^{1}$ and ENK conceived and designed the study. MOO, BIB ${ }^{1}$, JDK, DC and $\mathrm{BIB}^{2}$ acquired the data. $\mathrm{MOO}, \mathrm{BIB}^{1}, \mathrm{BIB}^{2}$ and $\mathrm{ENK}$ analyzed and interpreted the data. MOO and ENK drafted the manuscript. $\mathrm{BIB}^{1}$, JDK, DC and $\mathrm{BIB}^{2}$ revised the manuscript. $\mathrm{BIB}^{1}, \mathrm{BIB}^{2}$ and ENK approved the final version of the manuscript. All authors read and approved the final manuscript.

\section{Conflicts of Interest}

The authors declare that there is no conflict of interest. 


\section{References}

[1] World Health Organization (2010) Early Warning Indicators of HIV Resistance to AntiRetroVirals.

[2] World Health Organization (2014) WHO Recommendation for the Management of HIV Resistance to ARVs. http://www.global-campaign.org

[3] Kamangu, N.E., Bulanda, I.B., Bongenia, I.B., Botomwito, T.H., Mvumbi, L.G., De Mol, P., Vaira, D., Hayette, M.P. and Kalala, L.R. (2015) Molecular Epidemiological Profile of the HIV Infection Type 1 among Patients Naïve of Treatment in Kinshasa. Annals of African Medicine, 8, 2136-2141. https://doi.org/10.4236/oalib.1101564

[4] Kamangu, N.E., Chatté, A., Susin, F., Boreux, R., Kalala, L.R., Mvumbi, L.G., De Mol, P., Vaira, D. and Hayette, M.P. (2015) Genetic Diversity and Antiretroviral Drug Resistance among Drug-Naïve HIV Type 1 Infected Patients Attending Clinics in Kinshasa, Democratic Republic of Congo. Journal of HIV and AIDS, 1, 1-5. https://doi.org/10.16966/2380-5536.101

[5] Egger, M., May, M. and Chene (2002) Prognosis of HIV-1 Infected Patients Starting Highly Active Therapy: A Collaborative Analysis of Prospective Studies. The Lancet, 360, 119-129. https://doi.org/10.1016/S0140-6736(02)09411-4

[6] National AIDS Program against HIV/AIDS and Sexually Transmitted Infections (PNLS), Ministry of Public Health, Democratic Republic of Congo (DRC) (2016) National Guide for the Treatment of HIV Infection with AntiRetroVirals in Adolescents and Adults.

[7] Huguette, B. (2013) Perception of the National e HIV Support Policy by Doctors: Case of the General Provincial Hospital of Reference of Kinshasa. Dissertation Presented for Medical Degree at the Technological University Bel Campus, Kinshasa.

[8] Fokam, J., Billong, S.C., Bissek, A.C., Kembou, E., Milenge, P., Abessouguie, I., Nkwescheu, A.S., Tsomo, Z., Aghokeng, A.F., Ngute, G.D., Ndumbe, P.M., Colizzi, V. and Elat, J.B.N. (2013) Declining Trends in Early Warning Indicators for HIV Drug Resistance in Cameroon from 2008-2010: Lessons and Challenges for Low-Resource Settings. BMC Public Health, 13, 308.

http://www.biomedcentral.com/1471-2458/13/308 https://doi.org/10.1186/1471-2458-13-308

[9] Kamangu, E.N., Bulanda, B.I., Bongenya, B.I., Kateba, E.T., Okonda, M.O., Kasongo, V.N. and Kingombe, M.A. (2019) Evaluation of the Efficacy of the Phyto-Drug Djovikas: Traditional Treatment against HIV Infection. ARC Journal of AIDS, 4, 1-4.

[10] Kamangu, E.N., Kalala, R.L., Mvumbi, G.L., Vaira, D. and Hayette, M.P. (2017) Involvement of the Genetic Diversity of HIV-1 in the Virological Treatment Failure of First Line Antiretroviral in Kinshasa. World Journal of AIDS, 7, 23-33. https://doi.org/10.4236/wja.2017.71003 


\section{Abbreviation}

AIDS: Acquired Immuno Deficiency Syndrome,

ART: Anti Retro Viral Treatment,

ARV: Anti Retro Viral,

ATC: Ambulatory Treatment Center,

DRC: Democratic Republic of Congo,

EWI: Early Warning Indicator,

HIV: Human Immunodeficiency Virus,

HIVDR: HIV Drug Resistance,

LMIC: Low and Middle Income Country,

PLHIV: People Living with the Human Immunodeficiency Virus,

R-ARV: Resistance to ARV,

UNIKIN: University of Kinshasa,

VL: Viral Load,

WHO: World Health Organization. 